\title{
THE PRELIMINARY STUDY OF PESTICIDE MOSPILAN EFFECT ON THE GSTP1 GENE METHYLATION IN BOVINE LYMPHOCYTES
}

\author{
Halušková, J. ${ }^{1}$, Holečková, B. ${ }^{2}$, Staničová, J. ${ }^{1}$, Verebová, V. ${ }^{1}$ \\ ${ }^{1}$ Department of Chemistry, Biochemistry and Biophysics, Institute of Biophysics \\ ${ }^{2}$ Department of Biology and Genetics, Institute of Genetics \\ University of Veterinary Medicine and Pharmacy in Košice, Komenského 73, 04181 Košice \\ Slovakia
}

jana.haluskova@uvlf.sk

\section{ABSTRACT}

The epigenetic mechanisms represent a dynamic, reversible and heritable manner modulating gene expression during the life cycle of an animal organism. They generate the specific epigenetic marks which constitute so-called epigenome. One of the most studied epigenetic mechanisms/marks is DNA methylation which is, similarly as the whole epigenome, susceptible to environmental and nutritional influences. The aberrations of the DNA methylation profile may alter gene expression leading to pathologic consequences. Pesticides along with their pest-reducing effects may also negatively affect non-target organisms. In our preliminary study, we investigated an effect of the pesticide Mospilan on the DNA methylation of the bovine GSTP1 gene which plays an important role in the cell detoxification processes. The specific primers for the GSTP1 Methylation-specific PCR (MSP) analysis were proposed and tested with the DNA from the Mospilan-treated bovine lymphocytes. It seems that the pesticide with the concentration of $100 \mu \mathrm{g} \cdot \mathrm{ml}^{-1}$ did not induce DNA methylation changes in GSTP1 gene in bovine lymphocytes.

Key words: bovine; DNA methylation; GSTP1; Methylation-specific PCR; Mospilan; pesticide exposure

\section{INTRODUCTION}

During the development of an animal organism, the chemical changes of chromatin occur, which do not change the nucleotide sequences of DNA itself. As presented by G o d d a r d and W h i t e la w [6], these changes called epigenetic marks affect gene expression and hence the phenotype of the cell and are transmitted during the mitosis so that the daughter cells possess the same epigenetic marks as the parent cell. The epigenetic marks are established via specific cell mechanisms including DNA methylation; histone acetylation, methylation, and ubiquitylation; the action of non-coding RNAs and Polycomb/Trithorax group proteins; etc. The epigenetic mechanisms represent a heri- 
table, dynamic and reversible manner which realizes the modulation of gene expression during the life cycle and acts in such processes as: cell differentiation, morphogenesis, $\mathrm{X}$ chromosome inactivation, and genomic imprinting. They may be responsible also for the chromosome instability and the variability and adaptability of an organism. Although the genome of a cell is fairly stable, the epigenome is highly dynamic throughout life and is governed by a complex interplay of genetic and environmental factors [1].

DNA methylation is a form of epigenetic modification that involves the covalent addition of a methyl group to the 5 ' position of a cytosine base in a DNA sequence. The reaction is catalyzed by a specific group of enzymes called DNA methyltransferases (DNMT1, DNMT3a, DNMT3b, and DNMT3L), with S-adenosyl-methionine as the methyl donor. DNA methylation occurs mostly at CpG dinucleotides and to a lesser extent at $\mathrm{CpA}, \mathrm{CpT}$, or $\mathrm{CpC}$ dinucleotides. This DNA methylation is the most intensively studied epigenetic mechanism of gene regulation. It is commonly known that DNA methylation in the gene promoter regions leads to gene inactivation, but on the other hand, methylation in the body of genes induces gene activation. Accumulating lines of evidence indicate that DNA methylation is susceptible to nutritional and environmental influences and alterations in DNA methylation profiles can alter gene expression profiles leading to diverse phenotypes with the potential for increased/decreased productivity and disease risk $[2,9]$.

Pesticides are chemicals used to control noxious or unwanted living species. Therefore, they find use in agriculture, in public health for controlling vector-borne diseases, in an industry to protect machinery and products from biological degradation and in "do it yourself" activities, such as gardening [3]. They consist of one or more active agents and several adjuvants which improve their applicability and solubility. In addition to their pestreducing effects, however, they may also affect non-target organisms. These negative effects can be studied at the biochemical, physiological and/or molecular levels [17]. Up to now the pesticide effect on epigenetic marks/DNA methylation has been explored mostly in humans. The current evidence indicating that epigenetic modifications may mediate the pesticide effect on human health was reviewed by Collota et al. [3]. Van der Pla at et al. [18] showed for the first time that occupational exposure to pesticides is associated with differential genome-wide blood DNA methylation in humans. The 690 hypermethylated and 441 hypomethylated sites were revealed between case and control group in the investigation of intrauterine organochlorine pesticide (OCP)-dichlorodiphenyltrichloroethane (DDT) effect on the cord blood genome-wide DNA methylation [20]. Kwiatkowska et al. [10] observed a decrease in global DNA methylation level but an increase of TP53 gene promoter methylation in human peripheral blood mononuclear cells (PBMCs) exposed to glyphosate. As for animals, e.g. a significant global hypomethylation in the brain and gonad tissues of common carp exposed to the pesticide atrazine (ATR), chlorpyrifos (CPF) and their mixture was found compared to the control fish [19]. It was revealed that a mixture of pesticide permethrin and insect repellent N,N-diethyl-meta-toluamide (DEET) applied on the F0 generation of female rats increased pubertal abnormalities, testis disease, and ovarian disease in the F3 generation of animals. Moreover, 363 differential methylation regions (DMRs) indicating changes of DNA methylation pattern were present in the sperm of the F3 rat pesticide lineage [13].

The Methylation-specific PCR (MSP) represents the basic single nucleotide resolution technique to measure DNA methylation. It is based on an effect of sodium bisulphite which converts all unmethylated cytosines into uracils while methylated cytosines are unaffected. The subsequent amplification reaction employs the primers designed to amplify selectively the methylated and unmethylated DNA. Initially, when primer design for bisulphite-modified DNA is considered, the following two conditions must be remembered: i) primers must discriminate between native and bisulphite modified DNA, and ii) primers must discriminate between methylated and unmethylated alleles. Routinely, the primers are placed in the vicinity of the transcription start site (TSS). The rationale behind this is that methylation in the region around the TSS must have a profound effect on the gene transcription. In principle, MSP requires longer primers than standard PCR due to cytosine conversion. The optimal primer length for MSP ranges from $20 \mathrm{bp}$ to $30 \mathrm{bp}$ [4]. The consequence of bisulphite treatment is fragmentation of the DNA sample, so the resulting PCR product should not exceed $300 \mathrm{bp}$ [11]. At present, several free software for the design of MSP primers are available on the internet, e.g. MSPprimer, Beacon designer, Primo MSP, MethMarker, Methprimer, etc.

The glutathione S-transferases (GSTs) represent an im- 
portant group of enzymes. One of the GSTs major roles is cell protection against xenobiotic substances and products of oxidative stress, conjugating electrophilic and hydrophobic substrates and reactive oxygen species with glutathione. In addition, GSTs show non-catalytic functions modulating signalling processes that regulate cell proliferation, differentiation, and apoptosis $[5,12]$. On the base of the amino acid sequence and substrate specificity, 5 classes of GSTs namely GST alpha, mu, pi, theta, and zeta have been described. The bovine GSTP1 gene shows higher than $85 \%$ homology of amino acid sequence with humans [8].

So far, the aberrant DNA methylation of GSTP1 gene and its pathological effects have been demonstrated mostly in humans. In many cancer types, GSTP1 is affected by hypermethylation and, as a consequence, it has a low expression. Gurioli et al. [7] have given an overview on GSTP1 methylation studies in human cancer to have a complete information regarding this promising epigenetic biomarker. Qia o et al. [16] demonstrated that the methylation frequency of GSTP1 promoter region in patients with acuteon-chronic hepatitis B pre-liver failure (pre-ACHBLF) was significantly higher and the mRNA level significantly lower than in patients with chronic hepatitis $\mathrm{B}(\mathrm{CHB})$ or healthy controls (HCs). Hypermethylation in specific promoter CpG units and lower expression of GSTP1 gene have been found in patients with highly myopic cataract (HMC) compared to patients with age-related cataract (ARC) [21].

The inhibition of the GSTP1 gene expression as a consequence of aberrant methylation may have a significant negative effect on a bovine organism. Hence, in the current preliminary study, we investigated an effect of pesticide Mospilan on the GSTP1 gene methylation in bovine lymphocytes. The specific GSTP1 primers for the MSP were proposed and tested.

\section{MATERIALS AND METHODS}

\section{Blood collection and cultivation of blood lymphocytes with Mospilan}

Experiments were carried out with two healthy bull donors (Slovak spotted cattle, 5-6 months) and were conducted in accordance with the national and institutional guidelines for the protection of human subjects and animal welfare. The peripheral blood was collected in sterile heparinised syringes (5000 IU.ml ${ }^{-1}$, Zentiva, Czech Repub- lic). Whole blood cultures $(0.5 \mathrm{ml})$ were cultivated for $72 \mathrm{~h}$ at $37^{\circ} \mathrm{C}$ in $4 \mathrm{ml}$ of RPMI 1640 medium supplemented with L-glutamine and $25 \mathrm{mM}$ HEPES (GE Healthcare Hyclone Lab, Utah, USA), $1 \mathrm{ml}$ foetal calf serum, antibiotic and antimycotic mixed solution (100 U.ml-1 penicillin, $0.1 \mathrm{mg} \cdot \mathrm{ml}^{-1}$ streptomycin and $0.25 \mathrm{mg} \cdot \mathrm{ml}^{-1}$ amphotericin), and phytohaemagglutinin (Reagent Grade) (PHA, HA 15, $180 \mu \mathrm{g} \cdot \mathrm{ml}^{-1}$, Remel, Dartford, England). MOSPILAN ${ }^{\circledR} 20$ SP (20.2\% acetamiprid CAS 135410-20-7; $2.4 \%$ benzenesulfonic acid CAS 90194-45-9) was dissolved in water and applied to culture flasks at the concentration of $100 \mu \mathrm{g} \cdot \mathrm{ml}^{-1}$ for the last $24 \mathrm{~h}$ of cultivation. Negative control cultures were prepared by adding sterile water instead of pesticide.

\section{The lymphocyte DNA isolation and bisulphite modification}

The DNA from bovine lymphocytes was isolated using the Whole Blood Genomic DNA Extraction Kit (BioTeke Corporation) according to the manufacturer recommendations. The amount and purity of the DNA were measured by the nanophotometerTM P-class (IMPLEN). The bisulfite modification of the lymphocyte DNA was performed by means of the MethylEdge Bisulfite Conversion System (Promega).

\section{The primer design and the MSP}

The nucleotide sequence of the GSTP1 gene was obtained from the database ENSEMBL (http://www.ensembl. org/index.html; UMD3.1:29:46086542:46090605:1). The specific GSTP1 primers for the MSP were proposed using at that time accessible and free software MethMarker (http://methmarker.mpi-inf.mpg.de/). The PCR amplification was performed in the $25 \mu \mathrm{l}$ reaction volume containing 1 x concentrated GoTaq ${ }^{\oplus}$ G2 Hot Start Polymerase reaction buffer (Promega); $2.5 \mathrm{mM} \mathrm{MgCl} 2$ (Promega); $0.2 \mathrm{mM}$ dNTPs (Promega); $0.25 \mu \mathrm{M}$ of both GSTP1 forward and reverse primer (Sigma-Aldrich); $0.125 \mu$ l of the GoTaq ${ }^{\oplus}$ G2 Hot Start Polymerase (5 U. $\mu \mathrm{l}^{-1}$; Promega); nucleasefree water and about $30-60 \mathrm{ng}$ of the bisulphite-treated lymphocyte DNA. The amplification conditions were as follows: I/ $95^{\circ} \mathrm{C}, 2 \mathrm{~min}$; II $/ 35$ cycles: $95^{\circ} \mathrm{C}, 40 \mathrm{sec} ; 52$ and $55^{\circ} \mathrm{C}$ (for the primers amplifying the unmethylated and methylated GSTP1 gene, respectively), $30 \mathrm{sec} ; 72^{\circ} \mathrm{C}, 1 \mathrm{~min}$; and III $/ 72^{\circ} \mathrm{C}, 5 \mathrm{~min}$. The PCR amplification was run on the thermocycler Biometra (Analytik Jena). In each PCR reaction, the NTC (non-template control) with $1 \mu \mathrm{l}$ of wa- 
ter instead of lymphocyte DNA was included. The commercially available bovine DNA (Sigma-Aldrich) which is supposed to be unmethylated for the GSTP1 gene was also used in each PCR run. The products of amplification were identified in the $1.5 \%$ agarose gel with the addition of the GelRed ${ }^{\circledast}$ Nucleic Acid Stain (Biotium). The BenchTop 100 bp DNA ladder (Promega) was used as the molecular weight standard and the gels were photographed using the VWR GenoView (Major Science).

\section{RESULTS}

\section{The proposition of primers for the bovine} GSTP1 gene MSP analysis

Along with the GSTP1 ENSEMBL sequence, the specific initial parameters were entered into the MethMarker software, e.g. the length of primers: $17-30 \mathrm{bp}$; PCR product length: $90-300 \mathrm{bp}$; minimal number of CpGs: 2 ; minimal number of non-CpGs: 4; etc. More than 25 primer sets for the amplification of both the unmethylated and methylated GSTP1 gene were generated. The precise position of the bovine GSTP1 gene promoter and TSS within the ENSEMBL sequence was not available, either from the ENSEMBL or from the other databases (Database of Transcriptional Start Sites-DBTSS, Eukaryotic Promoter Database-EPD). However, the position of the GSTP1 $5^{\prime}$-untranslated region (5'-UTR) was known from the ENSEMBLE database. Out of the possibilities generated by means of MethMarker software, we have chosen primers amplifying the part upstream and with the slight lap to the
5 '-UTR (from the nucleotide 433 to 586 within the GSTP1 sequence without considering the primer sequences). This part should include mostly promoter sequences. The criteria for the primer option were the highest possible length and the PCR product with the optimal size. The sequences of the primers and the other information regarding the MSP are included in Table 1.

\section{The MSP analysis of the GSTP1 gene}

in the pesticide-treated bovine lymphocytes

The triplicates of the bisulphite-treated DNA samples isolated from the lymphocytes cultivated without (controls) and with Mospilan (experiment) were analysed by the MSP. In the case of the unmethylated GSTP1 gene, a 209 bp band should be amplified with the appropriate primers (Table 1). Indeed, a band with the length around $200 \mathrm{bp}$ was present in the PCR amplification profiles of all triplicates cultivated without but also in those cultivated with Mospilan. The Fig. 1 presents the electrophoretic analysis of the PCR amplification products obtained with primers for the unmethylated GSTP1 gene and the following bisulphite-treated template DNAs: the standard bovine control DNA, one control DNA isolated from the lymphocytes cultivated without Mospilan, and one pesticide-treated DNA. The PCR analysis with primers designed for amplification of the methylated GSTP1 gene should generate a $200 \mathrm{bp}$ band (Table 1). However, we revealed no band in the PCR amplification profiles generated with primers for the methylated GSTP1 gene of either the standard bovine DNA or all control and pesticide-treated DNA samples (results not shown).

Table 1. The properties of primers designed for the MSP analysis of the bovine GSTP1 gene by software MethMarker

\begin{tabular}{llcc}
\hline \multicolumn{1}{c}{ Primer name } & \multicolumn{1}{c}{\begin{tabular}{c}
\multicolumn{1}{c}{ Primer sequence } \\
{$\left[5^{\prime}-3^{\prime}\right]$}
\end{tabular}} & $\begin{array}{c}\text { Primer length } \\
{[\mathrm{bp}]}\end{array}$ & $\begin{array}{c}\text { Size of the PCR products } \\
{[\mathrm{bp}]}\end{array}$ \\
\hline Unmet $-\mathrm{F}$ & TATTAGAGTTTGGTGGATGTTTAGTAATT & 29 & 209 \\
Unmet $-\mathrm{R}$ & ACAACCTAAACCTTATAACAATAAACA & 27 & \\
\hline Met $-\mathrm{F}$ & GTTCGGCGGACGTTTAGTAATC & 22 & 200 \\
Met $-\mathrm{R}$ & GACCTAAACCTTATAACGATAAACG & 25 & \\
\hline
\end{tabular}

Unmet - F: the forward primer for the amplification of the unmethylated GSTP1 gene Unmet - R: the reverse primer for the amplification of the unmethylated GSTP1 gene Met - F: the forward primer for the amplification of the methylated GSTP1 gene Met - R: the reverse primer for the amplification of the methylated GSTP1 gene 


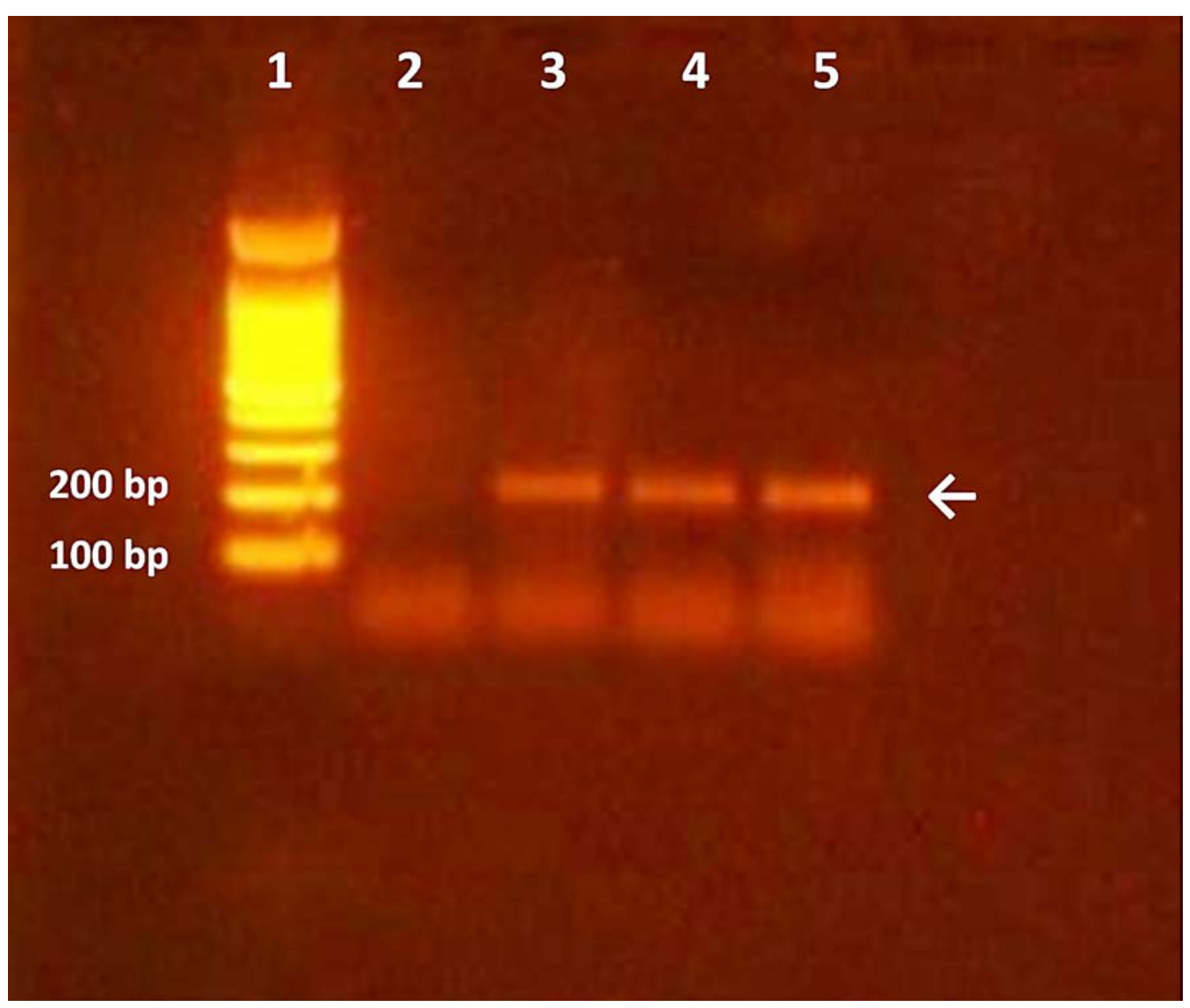

Fig. 1. The electrophoretic analysis of the PCR products after amplification of the bisulphite-treated bovine DNA isolated from the lymphocytes cultivated without/with Mospilan using the primers designed for the unmethylated GSTP1 gene

1-the molecular weight standard; 2-the NTC (water instead of the lymphocyte DNA); 3-the standard bovine DNA; 4-the control DNA of the lymphocytes cultivated without Mospilan; 5-the DNA of the lymphocytes cultivated with Mospilan. The arrow indicates the band with the size of $209 \mathrm{bp}$

\section{DISCUSSION}

In the present study, we analyzed for the first time an effect of a pesticide on the bovine GSTP1 gene methylation. According to our knowledge up to now, only one study aimed to analyze a pesticide effect on a gene methylation pattern in bovines. Pallotta et al. [14] studied the cytotoxicity and genotoxicity of a widely used organophosphate pesticide chlorpyriphos (CPF) in bovine spermatozoa. Along with the observations that the motility and in vitro fertilization rates were significantly reduced in spermatozoa exposed to CPF and the DNA fragmentation and putative chromatin deconstruction appeared to increase at higher pesticide concentrations, the researchers also revealed abnormalities in the methylation pattern. Specifically, while the NESP55-GNAS promoters displayed no DMRs relative to the control, the spermatozoa exposed to $10 \mu \mathrm{g} \cdot \mathrm{ml}^{-1}$ of CPF showed an increased methylation variance in one region of imprinted XIST promoter. In another study, it was revealed that melatonin reversed a decrease in bovine oocyte maturation induced by the broad-spectrum agricultural pesticide paraquat (PQ), via affecting epigenetic modifications [15]. The researchers observed that melatonin strongly inhibited an increase of trimethyl-histone $\mathrm{H} 3$ 
lysine 4 (H3K4me3) and a decrease of trimethyl-histone H3 lysine 9 (H3K9me3) level induced by PQ.

In our study, an expected PCR band which should be amplified with primers for the unmethylated GSTP1 gene was present in the amplification profiles of all controls as well as the pesticide-treated lymphocyte DNA samples. Simultaneously, an expected PCR band which should be amplified with primers designed for the methylated GSTP1 gene was absent in the amplification profiles of the same DNA samples. It suggests that, i) the analyzed CpG sites were unmethylated in all controls as well as in the pesticide-treated DNA samples, ii) no differences were revealed in the amplification profiles of the pesticide-treated when compared to the control DNA samples. It may indicate that pesticide Mospilan with the concentration of $100 \mu \mathrm{g} \cdot \mathrm{ml}^{-1}$ did not induce methylation changes in the CpG dinucleotides of the GSTP1. However, the amplification with the fully methylated bovine standard DNA as the template should be performed in order to verify the primers designed for the amplification of methylated GSTP1 gene. Further, we analysed only several CpG dinucleotides mostly within the promoter region, specifically those which are included in the primer sequences. In the future, the sequence analysis of the PCR products will be performed in order to analyse the methylation status of all CpG dinucleotides within the promoter part defined by the appropriate primers. Moreover, the other parts of the GSTP1 gene promoter and even the gene coding sequences may be analyzed employing the rest of primers designed by the MethMarker. Similarly, the other available software may be employed to design the MSP primers in the future. Finally, an effect of the lower (higher) concentrations of Mospilan as well as of the other widely used pesticides on the GSTP1 gene methylation will be investigated.

\section{CONCLUSIONS}

We proposed the specific primers for the MSP analysis of the bovine GSTP1 gene and tested them in the study of pesticide Mospilan influence on the induction of the gene methylation alteration. The pesticide with the concentration of $100 \mu \mathrm{g} \cdot \mathrm{ml}^{-1}$ probably did not induce DNA methylation changes in GSTP1 gene in bovine lymphocytes.

\section{ACKNOWLEDGEMENT}

This study was supported by the Scientific Grant Agency of the Slovak Republic under grant No. 1/0242/19.

\section{REFERENCES}

1. Bernstein, B. E., Meissner, A., Lander, E. S., 2007: The mammalian epigenome. Cell, 128, 4, 669-681. DOI: 10.1016/j.cell. 2007.01.033

2. Choi, S.-W., Friso, S., 2010: Epigenetics: a new bridge between nutrition and health. Adv. Nutr., 1, 8-16. DOI:10.3945/ an.110.1004.

3. Collotta, M., Bertazzi, P.A., Bollati, V., 2013: Epigenetics and pesticides. Toxicology, 307, 35-41. DOI: 10.1016/j.tox. 2013.01.017.

4. Davidović, R.S., Božović, A.M., Mandušić, V. Lj., Krajnović, M.M., 2014: Methylation-specific PCR: four steps in primer design. Cent. Eur. J. Biol., 9, 12, 1127-1139. DOI: 10.2478/s11535-014-0324-z.

5. Di Pietro, G., Magno, L.A. V., Rios-Santos, F., 2010: Glutathione S-transferases: an overview in cancer research. Expert Opin. Drug Metab. Toxicol., 6, 153-170. DOI: 10.1517/ 17425250903427980.

6. Goddard, M.E., Whitelaw, E., 2014: The use of epigenetic phenomena for the improvement of sheep and cattle. Front. Genet., 5, 247. DOI: 10.3389/fgene.2014.00247.

7. Gurioli, G., Martignano, F., Salvi, S., Costantini, M., Gunelli, R., Casadio, V., 2018: GSTP1 methylation in cancer: a liquid biopsy biomarker? Clin. Chem. Lab. Med., 56, 5, 702-717. DOI: 10.1515/cclm-2017-0703.

8. Hernando, N., Martin-Alonso, J.M., Ghosh, S., Coca-Prados, M., 1992: Isolation of a cDNA encoding a glutathione s-transferase (GST) class-Pi from the bovine ocular ciliary epithelium. Exp. Eye Res., 55, 711-718.DOI: 10.1016/00144835(92)90175-R

9. Jang, H., Serra, C., 2014: Nutrition, epigenetics, and diseases. Clin. Nutr. Res., 3, 1, 1-8. DOI:10.7762/cnr.2014.3.1.1.

10. Kwiatkowska, M., Reszka, E., Wozniak, K., Jabłonska, E., Michałowicz, J., Bukowska, B., 2017: DNA damage and methylation induced by glyphosate in human peripheral blood mononuclear cells (in vitro study). Food Chem. Toxicol., 105, 93-98. DOI:10.1016/j.fct.2017.03.051. 
11. Li, L.C., Dahiya, R., 2002: MethPrimer: designing primers for methylation PCRs. Bioinformatics, 18, 11, 1427-1431. DOI: 10.1093/bioinformatics/18.11.1427.

12. Laborde, E., 2010: Glutathione transferases as mediators of signalling pathways involved in cell proliferation and cell death. Cell Death Differ., 17, 9, 1373-1380. DOI: 10.1038/ cdd.2010.80.

13. Manikkam, M., Tracey, R., Guerrero-Bosagna, C., Skinner, M.K., 2012: Pesticide and insect repellent mixture (permethrin and DEET) induces epigenetic transgenerational inheritance of disease and sperm epimutations. Reprod. Toxicol., 34, 4, 708-719. DOI: 10.1016/j.reprotox.2012.08.010.

14. Pallotta, M. M., Barbato, V., Pinton, A., Acloque, H., Gualtieri, R., Talevi, R. et al., 2019: In vitro exposure to CPF affects bovine sperm epigenetic gene methylation pattern and the ability of sperm to support fertilization and embryo development. Environ. Mol. Mutagen., 60, 1, 85-95. DOI: 10.1002/ em.22242.

15. Pang, Y-W., Jiang, X-L., Wang, Y-Ch., Wang, Y-Y., Hao, H-S., Zhao, S-J. et al., 2018: Melatonin protects against paraquat-induced damage during in vitro maturation of bovine oocytes. J. Pineal. Res., 66, e12532. DOI: 10.1111/jpi.12532.

16. Qiao, Ch-Y., Li, F., Teng, Y., Zhao, J., Hu, N., Fan, Y-Ch. et al., 2018: Aberrant GSTP1 promoter methylation predicts poor prognosis of acute-on-chronic hepatitis B pre-liver failure. Clin. Exp. Med., 18, 51-62. DOI: 10.1007/s10238-0170466-1.
17. Schwarzbacherová, V., Wnuk, M., Lewinska, A., Potocki, L., Zebrowski, J., Koziorowski, M. et al., 2016: Evaluation of cytotoxic and genotoxic activity of fungicide formulation Tango ${ }^{\star}$ Super in bovine lymphocytes. Environ. Pollut., 1-9. http: DOI: 10.1016/j.envpol.2016.09.057.

18. van der Plaat, D. A., de Jong, K., de Vries, M., van Diemen, C.C., Nedeljković, I., Amin, N. et al., 2018: Occupational exposure to pesticides is associated with differential DNA methylation. Occup. Environ. Med., 75, 6, 427-435. DOI: 10. 1136/oemed-2017-104787.

19. Xing, H., Wang, C., Wu, H., Chen, D., Li, S., Xu, S., 2015: Effects of atrazine and chlorpyriphos on DNA methylation in the brain and gonad of the common carp. Comp. Biochem. Phys. C., 168, 11-19. DOI: 10.1016/j.cbpc.2014.11.002.

20. Yu, X., Zhao, B., Su, Y., Zhang, Y., Chen, J., Wu, W. et al., 2018: Association of prenatal organochlorine pesticide dichloro-diphenyl-trichloroethane exposure with foetal genome-wide DNA methylation. Life Sci., 200, 81-86. DOI: 10.1016/j.lfs.2018.03.030.

21. Zhu, X., Li, D., Du, Y., He, W., Lu, Y., 2018: DNA hypermethylation-mediated downregulation of antioxidant genes contributes to the early onset of cataracts in highly myopic eyes. Redox. Biol., 19, 179-189. DOI: 10.1016/j.redox.2018.08.012.

Received April 5, 2019

Accepted May 24, 2019 